\title{
MUDANÇAS INTITUCIONAIS E INOVAÇÃO AMBIENTAL: A POLÍTCA NACIONAL DE RESÍDUOS SÓLIDO E O REAPROVEITAMENTO ENERGÉTICO DE RESÍDUOS
}

\author{
Jorge Nogueira de Paiva Britto
}

\begin{abstract}
Resumo: O artigo discute a importância do reaproveitamento energético de resíduos sólidos como alternativa para a dinamização do setor de tratamento de resíduos, em consonância com as orientações da Polítca Nacional de Resíduos Sólido, por meio de um fortalecimento dos vínculos entre a política ambiental e política industrial e tecnológica. Particular importância é atribuída às estratégias de empresas atuantes na gestão de resíduos sólidos que apontam nessa direção e à identificação de alternativas tecnológicas para viabilizar esse reaproveitamento.
\end{abstract}

Palavras Chaves: Resíduos Sólidos; Reaproveitamentoe Energético; Política Ambiental; Inovação.

\begin{abstract}
The paper discusses the importance of energy recovery from solid waste as an alternative to boost the waste treatment sector, according to the guidelines of the Brazilian National Solid Waste Policy, through a strengthening of the linkages between the environmental policy and the industrial policy. Particular importance is attributed to the strategies of companies operating in the management of solid waste that seems to exploit these opportunities and to the identification of alternative technologies that might be mobilized to increase this recovery.

Key-words: Solid Waste; Energy Recovery; Environmental Policy; Innovation.
\end{abstract}

Área de classificação do Journal of Economic Literature: Q53, Q55 e Q57

\section{Introdução}

As sinalizações das políticas têm uma influência direta na dinamização do tratamento de resíduos sólidos, podendo-se destacar a intensificação de regulamentações ocorrida nas últimas décadas no Brasil. Esse processo decorre tanto da integração do país a uma série de disposições legais internacionais, como em função de pressões criadas pelo próprio processo de desenvolvimento e pela necessidade de fortalecer a competitividade da indústria e de ampliar a oferta de serviços públicos em condições ambientalmente mais sustentáveis. Neste contexto, o raproveitamento energético de resíduos sólidos constitui um aspecto importante, que reforça os vínculos entre a política ambiental e política industrial e tecnológica, com desdobramentos importantes em termos da criação de estímulos à dinamização desta atividade.

A responsabilidade pelo recolhimento e eliminação de resíduos sólidos no Brasil é atribuída à esfera municipal. Os municípios são responsáveis por selecionar locais para implementação de aterros sanitários, bem como por organizar a coleta de todos os resíduos (por si ou através de um contratante privado) e por descartá-los adequadamente. A operação de aterros sanitários nos municípios deve ser compatível com as leis federais, estaduais e municipais, bem como com os regulamentos ambientais, devendo cumprir normas relativas à cobrança, controle e eliminação de resíduos sólidos urbanos, incluindo resíduos perigosos e tóxicos, resíduos hospitalares e resíduos industriais. A Política Nacional de Resíduos Sólidos (PNRS) incorpora uma abordagem sistêmica para a gestão de resíduos sólidos, incluindo a repartição de responsabilidades pela gestão dos resíduos ao longo de todo o ciclo de vida dos produtos, com um forte foco em procedimentos de logística reversa. Observa-se também uma tendência a que a venda de tecnologias para tratamento e reaproveitamento de resíduos domésticos e industriais contemple, cada vez mais, a provisão de modelos de gestão integrada.

A expansão do mercado de tratamento de resíduos favoreceu nos últimos anos um processo de consolidação no setor no Brasil. A produção de resíduos sólidos no Brasil em 2010 atingiu de aproximadamente 61 milhões de toneladas-ano, 65\% dos quais de conteúdo orgânico, contemplando um mercado para a coleta e disposição de resíduos sólidos urbanos, avaliado em R \$ 6,5 bilhões, enquanto o de resíduos comerciais e industriais movimentaria entre R\$ 3-4 bilhões, segundo informações da ABRELPE (Associação Brasileira de Empresas de Limpeza Pública e Resíduos Especiais), O crescimento estimado dessemercado ocaliza-se na faixa de 7-10\% ao ano. Na esfera empresarial, consolida-se nos últimos anos a atuação de grandes grupos econômicos com atuação diversificada nestes mercados, geralmente ancorados em alguma atividade que lhes garante um grande fluxo de receitas. Com recursos próprios ou com o apoio de fundos de investimentos, observa-se uma tendência à criação de holdings ambientais, om múltiplas formas de atuação consorciada e tendência à abertura do capital, para viabilizar 
uma aceleração de seu crescimento e para fortalecer a capacidade de exercício de lobby no mercado das concessões de serviços públicos.

Tendo estas tendências como "pano de fundo", o artigo está estruturado em cinco seções. A primeira seção apresenta uma sistematização das características estruturais do setor de tratamento de resíduos sólidos, ressaltando a natureza das tecnologias utilizadas e a configuração da cadeia produtiva associadas. A segunda seção discute as mudanças recentes no arcabouço institucional e na orientação das políticas públicas para o setor, atribuindo particular ênfase às orientações presentes no instrumento normativo básicos dessas políticas, a PNRS. A terceira seção apresenta informações sobre a evolução recente do mercado de serviços de tratamento de resíduos no Brasil, ressaltando a participação de agentes privados nesse mercado e atuação de holdings ambientais com atuação diversificada, cujas estratégias contemplam crescentemente o reaproveitamento energético de resíduos. A quarta seção apresenta tendências relativas ao desenvolvimento tecnológico no setor, avançando no sentido da identificação da relevância do reaproveitamento energético na dinâmica inovativa setorial. Uma última seção identifica algumas implicações normativas da análise.

\section{1 - Características estruturais dos setores de tratamento de resíduos sólidos}

É possível classificar os Resíduos Sólidos em termos de tipo, fonte e propriedades. Em termos dos tipos, os resíduos sólidos são classificados em dois grupos. Os Resíduos Classe I - Perigosos são aqueles que apresentam inflamabilidade, corrosividade, reatividade, toxicidade ou patogenecidade, ou seja, são aqueles que apresentam risco à saúde pública, provocando mortalidade, incidência de doenças ou acentuando seus índices ou riscos ao meio-ambiente, quando gerenciados de forma inadequada. Já os Resíduos Classe II - Não perigosos subdividem-se em resíduos classe II A - Não inertes e resíduos classe II B - Inertes. Os Resíduos Classe II A - Não inertes são aqueles que não se enquadram nas classificações de resíduos classe I - Perigosos ou de resíduos classe II B - Inertes. Esses resíduos podem ter propriedades de biodegradabilidade, combustibilidade ou solubilidade em água. Os Resíduos Classe II B - Inertes são aqueles resíduos que quando submetidos a um contato dinâmico ou estático com água destilada ou deionizada, à temperatura ambiente, não tenham nenhum de seus constituintes solubilizados a concentrações superiores aos padrões de potabilidade da água, excetuando-se aspecto, cor, turbidez, dureza e sabor.

Pode-se também classificar os resíduos sólidos, quanto à fonte geradora, em três categorias: resíduos urbanos, resíduos sólidos industriais e resíduos especiais. Distingue-se, desse modo, os Resíduos Urbanos, que podem ter origem domiciliar, ser provenientes da varrição e da limpeza de logradouros públicos, ou ser resultantes da poda ou capina, de terminais de transporte, da construção civil ou de serviços de saúde. Os Resíduos Industriais podem ser provenientes das indústrias de transformação, incluindo rejeitos radioativos ou de atividades agrícolas. Por fim, os Resíduos Especiais incluem pneus, pilhas e baterias, lâmpadas e componentes de origem eletroeletrônica.

Os Resíduos Sólidos podem também ser classificados segundo as suas propriedades, considerando diversos atributos. A Composição Gravimétrica traduz o percentual de cada componente do resíduo em relação à massa total da amostra realizada. Esta característica é importante no caso de resíduos bastante heterogêneos, como é o caso dos RSU. A partir da composição gravimétrica do lixo podem-se elaborar projetos de redução, de segregação na origem e de aproveitamento dos materiais potencialmente recicláveis, além de subsidiar a escolha do tratamento e destinações finais mais adequados aos componentes do lixo. Outras características importantes dos resíduos sólidos podem ser destacadas: 1) a Massa específica, dada pela razão entre a massa do resíduo e seu volume ocupado, geralmente expresso em $\mathrm{kg} / \mathrm{m}^{3}$, que constitui uma variável importante para dimensionar equipamentos e instalações; 2) a Compressividade dada por quanto o volume do resíduo pode reduzir quando este sofre compactação; 3) o Teor de umidade que representa a quantidade de água presente nos resíduos, medida em percentual da massa total dos mesmos; 4) o Poder calorífico, que indica a quantidade de calor ou energia que pode se desprender de determinada massa de resíduo quando este é submetido à queima; 5) o Potencial hidrogeniônico $(\mathrm{pH})$, que indica o teor de acidez ou alcalinidade dos resíduos, situando-se, em geral, na faixa de 5 a 7, para o lixo domiciliar, e a composição química, que consiste principalmente na 
determinação dos teores de carbono (associados à eficiência dos processos de decomposição biológica ou incineração), nitrogênio (relacionado ao poder calorífico), hidrogênio (que indicam parcialmente a quantidade de materiais plásticos presentes nos resíduos), oxigênio (também relacionado ao poder calorífico e que influencia os processos de combustão dos resíduos), enxofre (geradores de poluição do ar ao se converterem em dióxido de enxofre, SiO2, durante a incineração), cloro (que definem as quantidades de ácido clorídrico geradas pela queima dos resíduos); 6) Características biológicas dós resíduos que são determinadas pela população microbiana e agentes patogênicos presentes no lixo.

A Figura 1 ilustra a sequência das diversas etapas associadas à gestão de resíduos sólidos. Em termos das condições de "entrada” no sistema, é possível distinguir os resíduos urbanos, os resíduos de origem comercial ou industrial e os resíduos perigosos. Os resíduos urbanos são gerados a partir dos serviços de limpeza, realizados por prestadores de serviços de coleta e varrição, enquanto os resíduos de origem comercial ou industrial são gerados a partir de atividades de separação e gerenciamento; já os resíduos perigosos são coletados diretamente de atividades dedicadas de gerenciamento, remediação e coleta desses resíduos, cuja geração está sujeita a controles mais rígidos. A geração desses diferentes tipos de resíduos vincula-se, portanto, a diferentes tipos de serviços que tendem a ser prestados por agentes especializados.

Em relação à etapa de disposição final de RSU, o aterro sanitário é o método mais difundido, por ser considerada a solução mais econômica quando comparado a outros processos. No Brasil destaca-se a priorização do uso de aterros sanitários, favorecendo a produção e queima de biogás em projetos do denominado "mercado de carbono". Neste sentido, é possível identificar diferentes tipos de aterros em função do tipo de resíduo depositado. O Aterro Classe I destina-se aos resíduos considerados perigosos de alta periculosidade, como cinzas de incineradores, resíduos inflamáveis, tóxicos e etc. Neste caso, o a aterro é dotado de uma estrutura capaz de minimizar os riscos de contaminação do lençol freático, pois é operado com cobertura total a fim de evitar a formação de percolado devido a incidência das águas pluviais e ainda possui um sistema de dupla impermeabilização com manta PEAD (polietileno de alta densidade), protegendo o solo e lençóis de águas subterrâneas. Este tipo de aterro deve estar em conformidade com a NBR-8418 e NBR-10157 que define as exigências quanto aos critérios de projeto, construção e operação de aterros industriais classe I. O Aterro Classe II - A abrange o destino de resíduos não perigosos e não inertes e também resíduos domiciliares, possuindo como características a impermeabilização com argila e geomembrana de PEAD, sistema de drenagem e tratamento de efluentes líquidos e gasosos, além de um programa de monitoramento ambiental. Os Aterros Classe II - B destinam-se a resíduos inertes, e, devido essa característica dos resíduos, dispensa a impermeabilização do solo. Esse aterro possui sistema de drenagem de águas pluviais e um programa de monitoramento ambiental que contempla o acompanhamento geotécnico (movimentação, recalque e deformação) do maciço de resíduos.

Os aterros sanitários envolvem um método de disposição de resíduos sólidos no solo que segue rígidas normas de operação e critérios de engenharia visando controlar os impactos ambientais e proteger a saúde pública. Nos diversos tipos de aterros, destaca-se a utilização de técnicas de Landfarming, envolvendo sistemas de tratamento que recorrem a propriedades físicas e químicas do solo, utilizando a intensa atividade microbiana existente neste meio de forma a promover a biodegradação, desintoxicação, transformação e imobilização dos constituintes dos resíduos tratados, minimizando os riscos de contaminação. Os resíduos são tratados e incorporados na superfície ou no interior do horizonte superficial do solo, acompanhadas a práticas de manejo e monitoramento constantes. Os aterros sanitários mais modernos já têm um controle de gás, sistema de coleta de chorume, monitoramento de águas subterrâneas e estão localizados estrategicamente para tirar proveito das condições naturais de geologia.

Uma etapa intermediária para o aproveitamento econômico dos resíduos envolve a logística de coleta e transbordo desses resíduos no intuito de transferi-los para atividades de valorização e tratamento final. Essa logística, no caso de resíduos urbanos e de origem comercial e industrial, envolve atividades de coleta tradicional, coleta seletiva, coleta de recicláveis, entrega voluntária e logística reversa. Na etapa subsequente de valorização e tratamento final, os resíduos urbanos e de origem comercial e industrial são depositados em aterros de diferentes tipos, geridos por agentes específicos, e processados em plantas de triagem e produção de CDR, em plantas de gestão anaeróbica e em plantas de compostagem. No caso de 
resíduos perigosos, é possível distinguir a gestão de aterros especializados, incluindo o tratamento de solos contaminados, e o processamento de resíduos químicos. No caso de aterros especializados em resíduos perigosos, destacam-se atividades de biorremediação, enquanto os resíduos químicos são destinados a unidades de coprocessamento.

Desse modo, as atividades de valorização e tratamento final de resíduos incluem atividades de Gestão de aterros, Geração de energia e Reciclagem de materiais. No caso do processamento de resíduos urbanos e de origem comercial e industrial, são gerados quatro tipos de "produtos": 1) diversos tipos de materiais recuperados que são destinados a atividades de reciclagem (papel, madeira, plástico e metais); 2) combustível derivado diretamente de resíduos (CDR); 3) energia ou gás natural gerado diretamente a partir do processamento de resíduos; 4) fertilizantes gerados principalmente a partir de unidades de compostagem. Já no caso de resíduos perigosos, destaca-se a geração de um "blend” a partir do processamento de resíduos, utilizado principalmente como combustível alternativo para cimenteiras. Às atividades realizadas por agentes especializados nos diferentes estágios da cadeia de geração, coleta, processamento e conversão de resíduos articulam-se empresas fornecedoras de bens de capital e serviços (engenharia, consultoria, etc.).

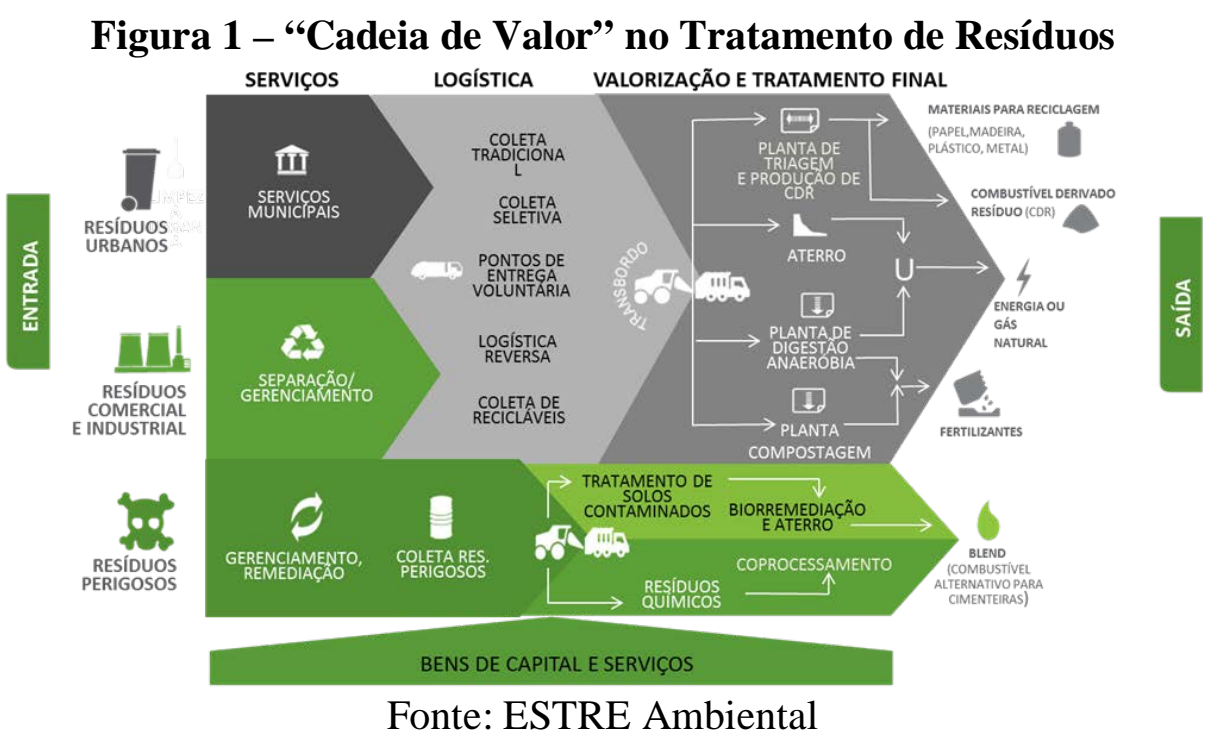

A partir da caracterização realizada, é possível discutir possíveis desdobramentos em termos de modelos para a Gestão de Resíduos Sólidos Urbanos (GRSU), compreendendo atividades relativas à tomada de decisões estratégicas e à organização do setor, abarcando instituições, políticas e instrumentos. Um modelo de GRSU requer a identificação dos diversos agentes sociais envolvidos e dos papéis a serem cumpridos por eles no processo, bem como a articulação entre estes agentes. Esse modelo envolve também a concretização de uma base legal e de mecanismos facilitadores à implementação das leis; a estruturação de mecanismos de financiamento para que as estruturas de gestão e de gerenciamento consigam se auto sustentar; a acessibilidade de informações à sociedade, como facilitador do controle social; e um sistema de planejamento integrado das atividades.

\section{2- Arcabouço Institucional e Políticas Públicas}

A incorporação da gestão dos resíduos sólidos no Brasil em diferentes instâncias do poder executivo é relativamente recente no Brasil. Com a criação do Ministério do Meio Ambiente, em 1992, as questões relativas aos resíduos sólidos passaram a integrar a pauta de preocupações dessa pasta e, em particular, de sua Secretaria de Qualidade Ambiental. A partir de 2003, com a criação do Ministério das Cidades, coube ao mesmo tratar da política de desenvolvimento urbano. No tocante ao manejo de resíduos sólidos urbanos, cabe ao Ministério das Cidades, por intermédio da Secretaria Nacional de Saneamento Ambiental, o atendimento a municípios com população superior a 50 mil habitantes ou integrantes de Regiões Metropolitanas - RMs, Regiões Integradas de Desenvolvimento - RIDEs ou 
participantes de consórcios públicos afins. Já os municípios de menor porte, com população de até 50 mil habitantes, têm seu atendimento viabilizado pelo Ministério da Saúde, por meio da Fundação Nacional de Saúde - Funasa. Com relação à implantação da política nacional de resíduos sólidos, o Ministério do Meio Ambiente também desenvolve diversas ações diretamente ou com parceiros, como é o caso da coordenação do Programa Federal de Resíduos Sólidos no Plano Plurianual (PPA). Com a reestruturação da Secretaria de Recursos Hídricos e Ambiente Urbano (SRHAU), em 2008, o MMA tem buscado atuar integrando as ações dos governos estaduais e municipais, apoiando a elaboração de estudos de regionalização e de planos estaduais de gestão integrada de resíduos sólidos; bem como estimulandoa implementação e fortalecimento de Consórcios Públicos; e a elaboração de Planos de Gestão Integrada de Resíduos Sólidos (PGIRS).

A Política Nacional de Resíduos Sólidos (PNRS) foi regulamentada pelo Decreto Federal n. ${ }^{\circ}$ 7.404de dezembro de 2010, após um processo de tramitação que se arrastou por mais de duas décadas, carecendo, ainda, de algumas resoluções, instruções e da implantação de planos de resíduos sólidos nas diversas instâncias de governo. A PNRS está alinhada aos esforços para transição para uma Economia Verde incorporando os princípios de prevenção, precaução, poluidor-pagador e protetor-recebedor, bem como uma visão sistêmica na gestão de resíduos (que considera variáveis ambiental, social, cultural, econômica, tecnológica e de saúde pública), tendo como foco o desenvolvimento sustentável, a ecoeficiência, a cooperação entre as diferentes esferas do poder público, o setor empresarial e demais segmentos da sociedade. Essa política enfatiza a responsabilidade compartilhada pelo ciclo de vida dos produtos, reconhecendo o resíduo sólido reutilizável e reciclável como bem econômico e de valor social, gerador de trabalho e renda e promotor de cidadania, num contexto de diversidades locais e regionais.

A PNRs estabelece alguns princípios orientadores e objetivos gerais, que incluem: i) uma abordagem sistêmica para gestão de resíduos sólidos com princípios holísticos; ii) a repartição de responsabilidades pela gestão dos resíduos gerados pela produção e consumo de bens ao longo de todo o ciclo de vida dos produtos; iii) o reconhecimento de que a gestão adequada dos resíduos gera benefícios econômicos e sociais mensuráveis e contribui para o desenvolvimento sustentável; iv) o princípio do "poluidor-pagador", utilizado na legislação, de modo a reduzir ambiguidades da legislação; v) princípios de razoabilidade e da proporcionalidade na definição da responsabilidade do produtor.A PNRS também estabelece diretrizes importantes para a gestão de resíduos, como a obrigatoriedade da formulação de Planos de Gestão de Resíduos Sólidos Municipais e Estaduais, a eliminação dos lixões, a implementação da logística reversa e a inclusão social dos catadores de materiais recicláveis como parte importante da cadeia de reciclagem no Brasil. Na agenda de sustentabilidade urbana, a implementação da PNRS tornouse uma prioridade nacional e estabeleceu metas deacabar com os lixões até 2014 e implantar também a coleta seletiva, a logística reversa e a compostagem dos resíduos úmidos em todo o país. Esses desafios estão postos principalmente para o setor privado e público, especialmente para os municípios, titulares dos serviços de limpeza pública.

No processo de gestão de resíduos sólidos, a PNRS estabelece também uma diferenciação entre diversos tipos de resíduos quanto à origem: a) resíduos sólidos urbanos, incluindo resíduos domiciliares originários de atividades domésticas em residências urbanas eresíduos de limpeza urbana originários da varrição, limpeza de logradouros e vias públicas e outros serviços de limpeza urbana; b) resíduos de estabelecimentos comerciais e prestadores de serviços; c) resíduos dos serviços públicos de saneamento básico; d) resíduos industriaisgerados nos processos produtivos e instalações industriais; e) resíduos de serviços de saúde, conforme definido em regulamento ou em normas estabelecidas pelos órgãos do Sisnama e do SNVS; f) resíduos da construção civilgerados nas construções, reformas, reparos e demolições de obras de construção civil, incluídos os resultantes da preparação e escavação de terrenos para obras civis; g) resíduos agrossilvopastoris gerados nas atividades agropecuárias e silviculturais, incluídos os relacionados a insumos utilizados nessas atividades; h) resíduos de serviços de transportes originários de portos, aeroportos, terminais alfandegários, rodoviários e ferroviários e passagens de fronteira; i) resíduos de mineração gerados na pesquisa, extração ou beneficiamento de minérios. De acordo com os princípios gerais da PNRS, os resíduos sólidos urbanos, os resíduos de estabelecimentos comerciais e prestadores de serviços e osresíduos dos serviços públicos e de saúde são de 
responsabilidade basicamente pública (municípios) enquanto os demais tipos são de responsabilidade basicamente privada, recaindo sobre os agentes geradores.

A PNRS definiu oito possíveis abrangências para os planos de resíduos: 1) Plano nacional de resíduos sólidos; 2) Planos estaduais de resíduos sólidos; 3) Planos microrregionais de resíduos sólidos; 4) Planos de resíduos sólidos de regiões metropolitanas; 5) Planos de resíduos sólidos de aglomerações urbanas; 6) Planos intermunicipais de resíduos sólidos; 7) Planos municipais de gestão integrada de resíduos sólidos; 8) Planos de gerenciamento de resíduos sólidos de natureza empresarial. Além disso, para os diferentes tipos de resíduos, esses planos deveriam estar baseados num conjunto de diretrizes, metas e estratégias. No caso dos resíduos sólidos urbanos, estas metas devem ser compatíveis com aquelas definidas no âmbito do Plano Nacional de Saneamento Básico (PNSB).

O gerenciamento dos resíduos sólidos urbanos envolve um conjunto de ações exercidas, direta ou indiretamente, nas etapas de coleta, transporte, transbordo, tratamento e destinação final ambientalmente adequada dos resíduos sólidos e disposição final ambientalmente adequada dos rejeitos, de acordo com Plano Municipal de Gestão Integrada de Resíduos Sólidos. Na gestão de resíduos sólidos, a PNRS estabelece uma hierarquia para destinação dos mesmos, priorizando-se a reutilização e reciclagem e deixando por último, apenas para os rejeitos, a disposição final em aterro sanitário. Especificamente quanto a esse aspecto, o artigo $9^{\circ}$ da PNRS estabelece uma clara hierarquização da não geração, redução, reutilização, reciclagem, tratamento dos resíduos sólidos e disposição final ambientalmente adequada dos rejeitos.

O tratamento deve incluir opções de revalorização do resíduo de forma a trazê-los de volta ao ciclo produtivo na forma de materiais (reciclagem mecânica e química), de composto orgânico (compostagem) e/o de energia (biometanização e incineração com recuperação de energia), para disposição final em aterros apenas dos rejeitos que não podem ser tratados e de preferência, inertes. Há necessidade de definição de metas de redução de rejeitos, seja por redução na geração ou pelo desenvolvimento tecnológico da cadeia de reciclagem. Também é importante o incentivo ao estabelecimento de plantas de revalorização e de reciclagem nas diferentes regiões do país, na forma de parques industriais recicladores, organizados com o apoio de governos estaduais e/ou de regiões metropolitanas. Aos consórcios intermunicipais e aos municípios cabe o resgate do trabalho dos catadores, por meio de sua incorporação aos sistemas de coleta seletiva e triagem de resíduos, promovendo a capacitação, organização em cooperativas e inserção social desses trabalhadores e erradicando de uma vez o trabalho de catadores nos locais de disposição final. O Governo também tem a função de planejar, padronizar a metodologia de coleta e tratamento dos dados na área, por meio do Sistema Nacional de Informações sobre a Gestão dos Resíduos Sólidos - SINIR, instrumento da PNRS.

Em função da regulamentação da PNRS, o Governo Federal, Estados e Municípios deverão elaborar seus planos para reaproveitamento, tratamento e eliminação de lixo orgânico e inorgânico, orientados pelos ditames da Política Nacional. No caso dos Estados, os planos da política deverão ter vigência indeterminada, antevendo um horizonte de vinte anos e prevendo revisões a cada quatro anos. Outra determinação relevante é o comprometimento maior dos estados para com a redução de resíduos, reciclagem, reutilização e outras formas sustentáveis de manejo, visando à redução dos rejeitos. Além da exigência de políticas locais, a lei determina que, até agosto de 2014, nenhum resíduo sólido seja mandado para aterros sanitários, apenas o material orgânico para compostagem (utilizável como adubo) ou para geração de energia (gás). Até essa data, também não poderão mais funcionar depósitos de lixo a céu aberto (lixões).

A PNRS determina também que a prioridade na gestão dos resíduos não é voluntária e sim obrigatória, prevendo a não geração, a redução, a reutilização, a reciclagem e o tratamento. Esta mesma lei traz definições para o gerenciamento de resíduos sólidos, caracterizado pelo conjunto de ações exercidas, direta ou indiretamente, nas etapas de coleta, transporte, transbordo, tratamento e destinação final ambientalmente adequada dos resíduos sólidos, de acordo com plano municipal de gestão integrada de resíduos sólidos ou com plano de gerenciamento de resíduos sólidos, exigidos na forma da Lei. A gestão e gerenciamento de resíduos sólidos segundo a PNRS baseiam-se numa hierarquia de prioridade que define os seguintes objetivos: não geração, redução, reutilização, reciclagem, tratamento dos resíduos sólidos e disposição final ambientalmente adequada dos rejeitos. A PNRS determina que os aterros 
devem receber apenas rejeitos, ou seja, aquilo que não é possível reciclar ou reutilizar, mobilizando estruturas que devem ter o preparo do solo para evitar a contaminação de lençol freático e possibilitando a captação do chorume que resulta da degradação do lixo. Além destas determinações, mesmo com a disposição final adequada, os RSU produzem emissões de gases causadores do efeito estufa, e para minimizar o problema os aterros deverão gerar energia com a captação dos gases gerados. Poderão ser utilizadas tecnologias visando à recuperação energética dos resíduos sólidos urbanos, desde que tenha sido comprovada sua viabilidade técnica e ambiental e que seja implantadoum programa de monitoramento da emissão de gases tóxicos aprovado pelo órgão ambiental. Com a implementação das medidas determinadas pela PNRS, um dos objetivos é alcançar um índice de reciclagem de resíduos da ordem de 20\% em 2015.

A PNRS estabelece também uma distinção entre resíduo (lixo que pode ser reaproveitado ou reciclado) e rejeito (o que não é passível de reaproveitamento), além de se referir a diferentes tipos de resíduo: doméstico, industrial, da construção civil, eletroeletrônico, lâmpadas de vapores mercuriais, agro-silvo-pastoril, da área de saúde e perigosos. Define, portanto, como principais objetivos a nãogeração, redução, reutilização e tratamento de resíduos sólidos; a destinação final ambientalmente adequada dos rejeitos; a diminuição do uso dos recursos naturais (água e energia, por exemplo) no processo de produção de novos produtos; a intensificação de ações de educação ambiental; o aumento da reciclagem no país; a promoção da inclusão social; a geração de emprego e renda para catadores de materiais recicláveis.

Destaca-se também o aperfeiçoamento do arcabouço institucional geral de apoio à intensificação de esforços inovativos dos agentes atuantes no setor. Nesta direção, uma inovação institucional importante pode ser associada à implantação do Programa INOVA Sustentabilidade, lançado em 2013. Este programa foi elaborado tendo como referência um conjunto abrangente de políticas relacionadas à área ambiental, integrando-se ao arcabouço geral das políticas industrial e de inovação. No campo ambiental, o programa se articula à Política Nacional sobre Mudanças Climáticas (Lei nº12.187 /2009), ao Programa Cerrado Sustentável (PCS), Plano Amazônia Sustentável (PAS) Plano de Ação para Prevenção e Controle do Desmatamento na Amazônia Legal (PPCDAM), Plano de Ação para Prevenção e Controle do Desmatamento e das Queimadas no Cerrado (PPCerrado) e Plano de Ação para Produção e Consumo Sustentável (PPCS). Ainda nessa direção, cabe mencionar as interfaces do programa com a Política Nacional de Resíduos Sólidos (PNRS) e o Plano Nacional de Saneamento (PLANSAB). Dentre as políticas de natureza mais ampla que orientam o programa, destaca-se a política industrial consubstanciada no Plano Brasil Maior (PBM) e apolítica de C,T\&I definida na Estratégia Nacional de Ciência, Tecnologia e Inovação (ENCTI) para o período 2012-2015.

O Programa INOVA Sustentabilidade tem como objetivo apoiar Planos de Negócio para desenvolver inovações que induzam a sustentabilidade no desenvolvimento brasileiro. Neste sentido, o programa direciona-se para o financiamento de P\&D e absorção tecnológica de natureza orientada, que resultem na produção e comercialização de produtos, processos e serviços inovadores, bem como de ações para a introdução dessas inovações no mercado. Quadro grandes áreas foram definidas como base para a geração de inovações: 1) Produção Sustentável; 2) Florestas; 3) Saneamento Ambiental; 4) Monitoramento de Desastres Ambientais. Na área de Produção sustentável são definidos como prioritários projetos direcionados para os seguintes campos: 1) Eficiência energética no setor industrial; 2) Produção sustentável mais eficiente de carvão vegetal; 3) Prevenção e controle de emissões atmosféricas; 4) Tratamento e redução no uso de substâncias tóxicas ou perigosas; 5) Coleta, tratamento, redução e reutilização de efluentes líquidos industriais; 6) Redução, reutilização e reciclagem de resíduos sólidos industriais e recuperação de áreas degradadas. Já na área de Saneamento Ambiental, são identificados como prioritários projetos em cinco linhas principais: 1) Tratamento, recuperação, reciclagem, aproveitamento energético e disposição de resíduos sólidos urbanos; 2) Projetos de sistemas de abastecimento de água com foco em controle de perdas e otimização das redes, no tratamento de água em regiões de escassez hídrica, incluindo dessalinização e tratamento de água salobra e na drenagem urbana; 3) Projetos de tratamento e valorização dos subprodutos gerados no tratamento de esgotos sanitários; 4) Coleta, transporte, triagem, descontaminação e tratamento de materiais em sistemas de logística reversa; 5) Remediação de solos contaminados, 
O programa direciona-se prioritariamente ao financiamento de projetos estruturados a partir da participação conjunta de três tipos de agentes. As Empresas Líderes do projeto são empresas independentes ou pertencentes a grupos econômicos com Receita Operacional Bruta igual ou superior a R\$16 milhões e Patrimônio Líquido igual ou superior a R\$ 4 milhões, que assumirão a responsabilidade pelo Plano de Negócios. As Empresas Parceiras são empresas com Receita Operacional Bruta menor que R\$ 16 milhões ou Patrimônio Líquido menor que R \$4 milhões, que participação do projeto em parceria com uma empresa líder. As Instituições de Ciência e Tecnologia (ICTs) podem ser órgãos/entidades da administração pública ou entidades privadas sem fins lucrativos. Os Planos de Negócio devem ter valor mínimo de R\$ 5 milhões, com prazo de execução de até 60 meses e deverão ser desenvolvidos integralmente no território nacional. O apoio do BNDES e da FINEP será limitado a 90\% do valor total. O BNDES e a FINEP disponibilizarão recursos no valor total de dois bilhões de reais para as operações contratadas no período de 2014 a 2016.

\section{3 - O mercado de Tratamento de Resíduos Sólidos}

A Tabela 1 mostra que, entre os anos de 2008 e 2012, houve um aumento em termos de geração de resíduos sólidos urbanos no Brasil, que alcançaram quase 62,3 milhões de toneladas no ano de 2012, com um crescimento de 1,3\%, de 2011 para 2012, índice que é superior à taxa de crescimento populacional urbano no país no período, que foi de 0,9\%. Observa-se também um aumento na quantidade de RSU coletados, que atingiu 56,6 milhões de toneladas no ano de 2012. Também no caso dos resíduos coletados, verifica-se uma atenuação do rimo de crescimento a partir de 2011. A comparação da quantidade total gerada e o total de resíduos sólidos urbanos coletados mostra que 6,2 milhões de toneladas de RSU deixaram de ser coletados no ano de 2012 e, por consequência, tiveram destino impróprio. A Tabela 1 mostra que houve um aumento de 2,0\% na quantidade de RSU coletados em 2012 relativamente a 2011. A comparação deste índice com o crescimento da geração de RSU mostra uma discreta evolução na cobertura dos serviços de coleta de RSU, chegando a 90,17\%, o que indica que o país caminha, ao menos, para universalizar esses serviços. A melhora observada nos serviços de coleta de RSU pode estar associada ao aumento nos recursos aplicados para esse fim, no país. A Tabela 2 mostra que houve um aumento de 31,9\% no valor dos recursos destinados à coleta de RSU no período de 2008 a 2012, com aceleração principalmente entre 2011-2012, sendo que neste último ano da série analisada o valor total foi de pouco mais de R\$ 8,67 bilhões, o que corresponde a R \$ 4,15 mês por habitante.

Tabela 1 - Geração e Coleta de RSU no Brasil

\begin{tabular}{|l|l|l|l|l|c|c|c|c|}
\hline Ano & $\begin{array}{l}\text { Geração } \\
\text { Milhões t/ano }\end{array}$ & $\mathbf{\%}$ & $\begin{array}{l}\text { Geração per } \\
\text { capita } \\
\text { Kg/hab/ano }\end{array}$ & $\mathbf{\%}$ & $\begin{array}{l}\text { Coleta } \\
\text { Milhões } \\
\text { t/ano }\end{array}$ & \% & $\begin{array}{l}\text { Coleta per capita } \\
\text { Kg/hab/ano }\end{array}$ & \% \\
\hline 2008 & 52,9 & - & 337,0 & - & 46,6 & - & 296,4 & - \\
\hline 2009 & 57,0 & $7,8 \%$ & 359,4 & $6,6 \%$ & 50,3 & $7,9 \%$ & 316,7 & $6,8 \%$ \\
\hline 2010 & 60,9 & $6,8 \%$ & 378,4 & $5,3 \%$ & 54,2 & $7,8 \%$ & 336,6 & $6,3 \%$ \\
\hline 2011 & 61,9 & $1,6 \%$ & 381,6 & $0,8 \%$ & 55,5 & $2,4 \%$ & 342,1 & $1,6 \%$ \\
\hline 2012 & 62,7 & $1,3 \%$ & 383,2 & $0,4 \%$ & 56,6 & $2,0 \%$ & 348,5 & $1,9 \%$ \\
\hline \multicolumn{7}{|c|}{ Fonte: ABRELPE (2012) } \\
\hline
\end{tabular}

Tabela 2 - Recursos Aplicados na Coleta de RSU no Brasil

\begin{tabular}{|lr|r|r|r|r|r|r|}
\hline Recursos & \multicolumn{1}{c|}{$\mathbf{2 0 0 8}$} & \multicolumn{1}{c|}{$\mathbf{2 0 0 9}$} & $\mathbf{2 0 1 0}$ & \multicolumn{1}{c|}{$\mathbf{2 0 1 1}$} & \multicolumn{1}{c|}{$\mathbf{2 0 1 2}$} & \multicolumn{1}{l|}{ Var } \\
\hline R\$ milhões/ano & 6.193 & 6.496 & 7.156 & 7.684 & 8.167 & $31,9 \%$ \\
\hline Valor equivalente por Hab. (R\$/mês) & 3,29 & 3,41 & 3,71 & 3,94 & 4,15 & $26,1 \%$ \\
\hline
\end{tabular}

O potencial econômico do mercado associado à gestão de resíduos sólidos no Brasil resultou num crescente interesse do setor privado pelo setor. Ao longo das duas últimas décadas, a iniciativa privada construiu no Brasil uma infraestrutura especializada na destinação de resíduos. A dinamização do mercado privado de tratamento de resíduos sólidos está fortemente vinculada com as diretrizes definidas, a partir de 2010, pela Política Nacional de Resíduos Sólidos. Este novo cenário abre oportunidades para novos empreendimentos em todas as etapas do gerenciamento de resíduos sólidos: limpeza urbana, 
logística reversa, triagem e reciclagem, recuperação de resíduos, desenvolvimento de novas aplicações para materiais reciclados, aproveitamento energético, transporte, etc., além de estruturas administrativas para planejamento e controle.

Um mapeamento recente elaborado pela Abetre (Associação Brasileira de Empresas de Tratamento de Resíduos), focando apenas empresas privadas que prestam serviços ao mercado, identifica 267 unidades receptoras de resíduos, operadas por 70 empresas privadas (ver Tabela 3). A Abetre é a entidade de classe que representa as empresas especializadas na destinação ambientalmente adequada de resíduos sólidos. Suas 21 associadas e empresas coligadas operam 54 unidades de tratamento, que representam cerca de $25 \%$ das plantas em operação, $50 \%$ do segmento de resíduos urbanos e $82 \%$ do segmento de resíduos industriais. A infraestrutura disponibilizada por essas empresas opera com um conjunto diversificado de tecnologias de destinação ambientalmente adequada, compreendendo disposição em aterro, coprocessamento, incineração, descontaminação e recuperação de materiais, recuperação energética, reciclagem, compostagem e outros tratamentos térmicos ou biológicos. A Figura 2 apresenta a distribuição de aterros para resíduos classe II A, podendo-se observar a maior concentração dos mesmos nos estados das regiões Sudeste e Sul.

Tabela 3 - Unidades Destinadoras de Resíduos Empresas privadas - Tecnologias e Localização (*)

\begin{tabular}{|l|c|c|}
\hline \multicolumn{1}{|c|}{ Tecnologia } & Unidades & Empresas \\
\hline Aterros para resíduos classe II A & 79 & 29 \\
\hline Aterros para resíduos classe I & 16 & 10 \\
\hline Incineradores industriais & 23 & 3 \\
\hline Unidades de blindagem para coprocessamento & 19 & 7 \\
\hline Cimenteiras licenciadas para coprocessamento & 35 & 13 \\
\hline Tratamento de resíduos eletroeletrônicos & 36 & 4 \\
\hline Outras tecnologias & 59 & 4 \\
\hline Total & $\mathbf{2 6 7}$ & $\mathbf{7 0}$ \\
\hline
\end{tabular}

Obs: (*) Algumas dessas unidades estão reunidas em plantas integradas, usualmente chamadas "Centrais de Tratamento de Resíduos" (CTR). Fonte: ABETRE (2013)

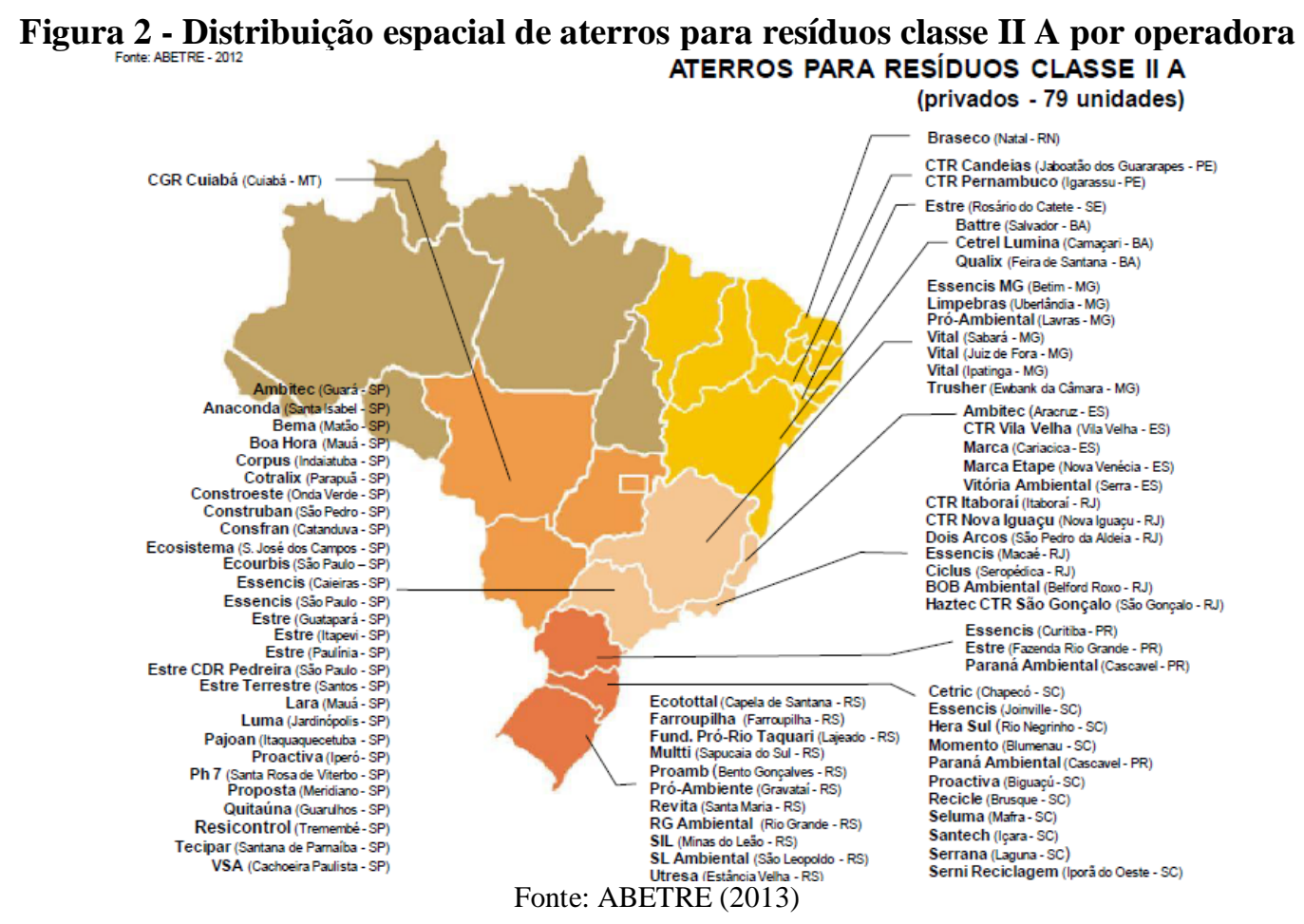

A Tabela 4 apresenta a evolução do mercado total e do mercado de resíduos industriais em termos de quantidades vinculadas ao mercado de prestação de serviços privados. Por um lado, observa-se um aumento da participação dos resíduos industriais, comparativamente aos resíduos urbanos. As informações apontam para um crescimento anual médio de 14,5\% em termos da quantidade processada e 21,7\% em receita entre 2004 e 2012 Segundo as informações apresentadas, a receita total nesse mercado evolui de R\$ 522 milhões em 2004 para R\$ 2.518 milhões em 2012. Informações sobre a evolução da 
receita com tratamento de resíduos entre 2005 e 2012 indicam para um crescimento expressivo: ao longo do período, a receita obtida com o tratamento de resíduos urbanos cresceu de R \$ 239 milhões para R 704 milhões; já a receita obtida com o tratamento de resíduos industriais cresceu de R 375 milhões para R\$ 1.804 milhões no mesmo período. Evidencia-se, assim, um maior crescimento do segmento de tratamento de resíduos industriais, comparativamente aos resíduos urbanos.Por outro lado em termos dos resíduos industriais, informações relativas a 2009 indicavam que 76\% dos resíduos equivaliam à disposição em aterro, $18 \%$ ao co-processamento, $3 \%$ à incineração e outros tratamentos térmicos e $3 \%$ a tratamentos biológicos e outros.

\section{Tabela 4 - Evolução do Mercado Total de Serviços Privados - Resíduos Industriais e Resíduos} Urbanos - 2004-2012.

\begin{tabular}{|c|c|c|c|c|c|c|c|c|c|}
\hline & 2004 & 2005 & 2006 & 2007 & 2008 & 2009 & 2010 & 2011 & 2012 \\
\hline \multicolumn{10}{|c|}{ Quantidade (milhões de toneladas) } \\
\hline RI - Resíduos Industriais & 2,9 & 3,2 & 4,5 & 6,0 & 7,1 & 8,0 & 8,9 & 9,9 & 10,8 \\
\hline RU - Resíduos Urbanos & 4,4 & 4,8 & 4,5 & 6,1 & 7,1 & 7,6 & 8,6 & 9,6 & 10,8 \\
\hline Mercado Total & 7,3 & 8,0 & 9,0 & 12,1 & 14,2 & 15,6 & 17,5 & 19,5 & 21,6 \\
\hline Crescimento Anual & & $9,3 \%$ & $12,2 \%$ & 34,9 & $17,5 \%$ & $10,0 \%$ & $12,0 \%$ & $11,1 \%$ & $11,0 \%$ \\
\hline \multicolumn{10}{|c|}{ Receita Bruta (R\$ milhões) } \\
\hline RI - Resíduos Industriais & 304 & 375 & 504 & 765 & 962 & 1.133 & 1.349 & 1.577 & 1.814 \\
\hline RU - Resíduos Urbanos & 218 & 239 & 223 & 307 & 376 & 420 & 502 & 594 & 704 \\
\hline Mercado Total & 522 & 614 & 729 & 1.072 & 1.360 & 1.544 & 1.850 & 2.172 & 2.518 \\
\hline Crescimento Anual & & 17,6 & $18,7 \%$ & $47,0 \%$ & $26,9 \%$ & 14,2 & $19,1 \%$ & $17,4 \%$ & $13,9 \%$ \\
\hline
\end{tabular}

Fonte: ABETRE (2013)

Na última década tem sido fortalecida no Brasil a presença de empresas de grande porte com atuação diversificada no mercado ambiental, incluindo o tratamento de resíduos sólidos, as quais operam como "holdings" ambientais. Estas empresas em geral apresentam uma especialização original em alguma atividade básica - geralmente associada ao setor de saneamento ou ao mercado de resíduos sólidos - a partir da qual procuram se diversificar - de forma autônoma ou em parceria com outras empresas - para novos segmentos do mercado ambiental que constituem oportunidades atrativas de negócios. Dada a necessidade de um elevado nível de capitalização - seja para atender exigências de processos licitatórios, seja para viabilizar processos de fusão-aquisição com outras empresas - muitas dessas empresas encontram-se vinculadas financeiramente a fundos de investimento ou a grupos empresariais de grande porte. Do mesmo modo, a grande capacidade de movimentação financeira dessas empresas, em conjunto com atuação das mesmas junto a grandes licitações públicas, reforça a importância da atuação consorciada e o exercício de lobby junto a diferentes instâncias de governo. Observa-se também uma tendência destas empresas abrir o seu capital para buscar recursos e poder crescer. Estas empresas, através dos investimentos realizados, dos projetos que gerenciam e das aquisições de serviços, insumos e equipamentos vinculados aos mesmos, funcionam como elos centrais (ou "empresas âncoras”) da cadeia produtiva vinculadas ao setor de tratamento de resíduos sólidos. Desse modo, o crescimento desse setor passa necessariamente pela intensificação dos investimentos dessas empresas e pela mobilização das suas estratégias de aquisições no sentido do fortalecimento dos demais elos daquelas cadeias. A parte que se segue apresenta uma análise das estratégias dos principais grupos empresariais atuantes mo segmento de resíduos sólidos que apresentam um padrão semelhante ao descrito, estruturando-se como holdings ambientais com variados graus de complexidade organizacional.

Criada em 2008, como braço do grupo Odebrecht, a Foz do Brasil tem como objetivo investir e operar projetos ambientais e prestar serviços com foco em três segmentos: i) Água e Esgoto através de parcerias e concessões públicas naqueles segmentos; ii) Operações Industriais, associadas à terceirização de Centrais de Utilidades; iii) Gestão de Resíduos, associada ao diagnóstico e remediação de áreas contaminadas, monitoramento de águas superficiais e subterrâneas e valorização energética dos resíduos sólidos urbanos. No fim de 2012, a Foz do Brasil eliminou o segundo nome e se tornou apenas Foz. A partir de outubro de 2013, porém, em uma decisão estratégica, retoma o nome do grupo e passa a ser denominada Odebrecht Ambiental. A empresa oferece soluções ambientais nos segmentos de tratamento de resíduos e efluentes industriais, saneamento (água e esgoto) e resíduos sólidos urbanos no Brasil e em outros países. Na área de saneamento, atua por meio de concessões públicas e privadas com prefeituras e 
companhias estaduais de saneamento. No segmento industrial, atua através da Lumina Soluções Ambientais, que atende a clientes dos setores de petróleo, mineração, siderurgia e petroquímica. No segmento Serviços Ambientais, destaca-se o primeiro contrato internacional para remediação de solo, tendo a Petrobras como cliente. Dentre a receita global do grupo Odebrecht, que atingiu R\$ 84,4 bilhões em 2012, a Odebrecht Ambiental foi responsável por um percentual de 1,7\% em 2012, equivalentes a uma receita de R\$ 1.435 milhões ou US\$ 702 milhões naquele ano. No segmento de Resíduos, a empresa diagnostica e remedia áreas contaminadas, monitora águas superficiais e subterrâneas e oferece valorização energética dos resíduos sólidos urbanos. Nesta área, a Odebrecht Ambiental também presta serviços de remediação de passivos ambientais e gerenciamento de resíduos para clientes como Petrobras, Transpetro, Vale, Braskem, Dow, Oxiteno, DuPont, Chesf e V\&M. O segmento de tratamento de resíduos vem crescendo a dois dígitos ao ano, com esta divisão sendo responsável por $15 \%$ das receitas da Odebrecht Ambiental, mas existe a expectativa de que esse percentual pode se elevar a 20\%. Dentre as apostas da empresa, destacam-se a busca de expansão no mercado internacional e esforços para elevar a participação em resíduos urbanos no Brasil.

O Grupo Solvi foi criado em 2006, quando o Grupo francês Suez optou por abrir mão de seus negócios na área de meio ambiente no Brasil e alguns de seus dirigentes criaram a empresaí, visando explorar oportunidades nas áreas de saneamento e resíduos sólidos. A Solví estrutura-se como holding controladora de empresas, que atuam nos segmentos de Resíduos, Saneamento e Valorização Energética e Engenharia. No segmento de resíduos, a Solvi opera nas áreas de resíduos públicos e resíduos industriais, atendendo mais de onze milhões de pessoas em diversos estados brasileiros e também no Peru. O faturamento geral do Grupo atingiu R\$ 2,44 bilhões em 20121, refletindo uma atuação bastante diversificada, na qual se destacam diversas empresas controladas ou coligadas. Dentre as empresas controladas pelo Grupo Solvi, a Vega Ambiental busca oferecer soluções ambientais integradas nas áreas de resíduos e saneamento, mobilizando aproximadamente 10 mil funcionários e atuando em Serviços de Coleta domiciliar, Coleta seletiva, Coleta de resíduos de serviço de saúde, Coleta de entulho, Coleta de contêineres, Tratamento de resíduos de saúde, Locação de caminhões (basculante, munck, retroescavadeira, trator, pá carregadeira, dentre outros), Varrição de vias e logradouros, Serviços diversos, Incinerador, Usina de triagem de lixo e Usina de reciclagem. O faturamento da Vega e coligadas atingiu R\$ 856 milhões em 2011, com investimentos de R\$ 200 milhões. A meta para 2016 é chegar a r\$ 1,6 bilhão. Na área de resíduos industriais e comerciais, duas empresas vinculadas ao grupo se destacam: a Essencis e a Koleta. A Essencis foi criada em 2001, constituindo uma empresa especializada em Gestão Ambiental Integrada de resíduos industriais procurando atuar em três grandes frentes: i) Soluções em Tratamento e Destinação Final de Resíduos, que concentra tecnologias de ponta para tratamento e destinação de resíduos; 2) Soluções em Engenharia e Consultoria, envolvendo negócios que contemplam a sustentabilidade de forma abrangente, como a realização de auditorias ambientais, gerenciamento de áreas contaminadas, gestão ambiental no mercado de óleo, gás e energia, gestão estratégica de água e gestão de emissões atmosféricas; 3) Soluções em Manufatura Reversa, que oferece tecnologia de desmontagem, descaracterização e reaproveitamento de partes recicláveis de equipamentos como geladeiras, congeladores, condicionadores de ar, eletroeletrônicos, veículos, máquinas, entre outros. A Koleta Ambiental S.A, criada em 2001, é especializada na prestação de serviços de logística, acondicionamento, coleta, transporte e destinação final de resíduos para a indústria, comércio, organizações de serviços e de serviços de saúde, sendo atualmente a maior empresa do Brasil no seu segmento. A OrganoSolvi é uma empresa especializada em resíduos orgânicos, formada a partir de uma joint-venture entre a GRI (pertencente ao Grupo Solví) e a Organoeste, atuando na implantação e operação de usinas de compostagem, uma opção de destinação de resíduos orgânicos classe II-A, não inertes, operando a partir de um processo inovador de base biotecnológica de aceleração de compostagem, através do qual resíduos poluentes retornam ao solo alimentando-o com seus nutrientes naturais. A Solví Valorização energética busca oferecer soluções inovadoras para a valorização de energia, incluindo usinas de captação ativa e queima controlada de biogás em aterros para projetos de créditos de carbono e/ou de geração de energia, usinas termelétricas alimentadas a biogás de aterros e estações de tratamento de esgoto, usinas Eólicas e Pequenas Centrais Hidrelétricas (PCHs) e usinas de geração de energia a partir de resíduos. Nos últimos anos, a empresa tem procurado introduzir inovações 
que permitem explorar novos mercados, particularmente no campo do aproveitamento de resíduos para fins energéticos.

A Haztec opera como holding ambiental, tendo sido criada em 1999 para atuar na prevenção de vazamentos em postos de combustíveis, atraindo posteriormente a atenção de investidores interessados no mercado de infraestrutura. A atuação inicial da Haztec estava vinculada às concessões de longo prazo no Rio de Janeiro, na área de resíduos sólidos e à área de geração de energia. Em 2013, a empresa de saneamento Foxx Inova Ambiental e a Haztec fecharam um acordo para a fusão. A partir dessa fusão, foi criada uma empresa integrada de gestão de resíduos, com foco na geração de energia a partir de resíduos e na disposição final em aterros sanitários, mobilizando 25.000 toneladas diárias de resíduos sob a sua gestão, posicionando-se como responsável por 15\% do RSU gerado no Brasil. A Foxx-Haztec está organizada em quatro linhas de negócios, cobrindo uma ampla gama de serviços ambientais essenciais. A área de Tratamento e Destinação de Resíduos envolve operações associadas ao Licenciamento, implantação e operação de aterros sanitários, Gerenciamento e Tratamento de Resíduos Perigosos, Gerenciamento Interno de Resíduos em unidades industriais, Tratamento de Resíduos Industriais e Comerciais Classe II, Tratamento de Resíduos Urbanos Classe II, Tratamento de Resíduos Sólidos de Serviços de Saúde, Aproveitamento Energético de biogás, Geração de Energia Limpa e Desenvolvimento de projetos de redução de gases de efeito estufa. A empresa gerencia atualmente mais de 30 mil toneladas de resíduos por dia em suas unidades no Rio de Janeiro, São Paulo, João Pessoa e Recife. O maior volume está concentrado nas Centrais de Tratamento de Resíduos (CTRs), um complexo industrial que reúne tecnologias integradas em diferentes processos de tratamento capazes de promover o gerenciamento completo dos resíduos, evitando a poluição e minimizando os impactos ambientais e sociais. O Gerenciamento de Resíduos também envolve serviços realizados nas instalações do cliente para promover o maior reaproveitamento e reciclagem dos resíduos gerados pelas empresas, considerando a avaliação de alternativas de tratamento e destinação final. Outra área de atuação da empresa envolve a operação de UREs - Unidades de Recuperação Energética, que utilizam um processo que transforma de forma direta os Resíduos Sólidos Urbanos (RSU) em energia elétrica, através do processo Waste to Energy (WtE). A primeira unidade para operação desse tipo está sendo montada em Barueri, São Paulo, com capacidade de tratamento: 825 toneladas/dia e capacidade de geração de energia: $20 \mathrm{MWh}$, um volume suficiente para abastecer uma cidade de 240 mil habitantes. A energia desse processo será comercializada no Mercado Livre de Energia Brasileiro, a partir de 2016. Para viabilizar a montagem da URE foram montadas parcerias estratégicas com a Keppel Seghers, líder mundial em tecnologia e equipamentos de WtE, com mais de 100 UREs em operação na Europa e Ásia, que será responsável pelo treinamento e assistência técnica, com a Engevix, uma das líderes no Brasil em Projetos EPC, e com a Fichtner responsável pela auditoria técnica de integração de projeto.

A Estre Ambiental é uma das maiores empresas de serviços ambientais do Brasil, com grande foco em gestão e valorização de resíduos, contando atualmente com 18.497 funcionários recebendo por dia, em média, 40 mil toneladas de resíduos, sendo 3.373 clientes privados e 107 clientes do setor público, atendendo a uma população de mais de 22 milhões de habitantes. A Estre tem se especializado em tratar adequadamente todos os tipos de lixo: doméstico, comercial, industrial, eletrônico, da construção civil e proveniente de serviços de saúde. A empresa gerencia atualmente 12 aterros sanitários em vários locais, principalmente na região Sudeste. Está presente também na Argentina e na Colômbia, no gerenciamento de aterros sanitários. Com 3,5 mil clientes, $55 \%$ da receita tem origem no setor privado e os demais $45 \%$ na área pública. A Estre possui também laboratórios de análises com certificação ISO 17025. A Estre direciona sua atuação para todo o ciclo do lixo, buscando as oferecer soluções para reduzir os impactos ambientais no cotidiano das cidades, com ênfase na geração de materiais reutilizáveis, compostos, novas formas de combustível e de energia a partir do lixo. No portfólio das empresas do grupo Estre aparecem oito unidades, sendo elas: 1) Estre Ambiental, quue atua na gestão de resíduos possui seis centros de gerenciamento de resíduos no Brasil,; 2) Resicontrol: que atua na gestão de resíduos industriais e urbanos, possuindo cinco unidades; 3) Água \& Solo, que atua com consultoria e auditoria ambiental e no diagnóstico e remediação de solos e águas; 4) Oxil, que atua na manufatura reversa; 5) Estação Ecologia que atua na reciclagem de resíduos da construção civil; 6) Estrans que atua na gestão de resíduos na Argentina; 7) Pollydutos que atua na instalação e manutenção de dutos para o transporte de gás, petróleo, 
gasolina e outros produtos destinados a geração de energia; 8) Estre Petróleo e Gás que atua em serviços de perfuração e recuperação de poços de petróleo e/ou gás com fornecimento de sondas terrestres. A Estre se encontra especializada em todos os tipos de lixo: doméstico, comercial, industrial, eletrônico, da construção civil e proveniente de serviços de saúde, operando Centros de Gerenciamento de Resíduos (CGRs), com base no conceito de TWM - Total Waste Management. A empresa recicla diversos materiais, transformando lixo em Combustível Derivado de Resíduos (CDR) ou em blend para cimenteiras e em breve, pretende também transformar estes resíduos em energia elétrica. É também especialista em manufatura reversa, oferecendo soluções para o reaproveitamento de produtos eletroeletrônicos. Dentre as suas unidades, destaca-se a Unidade de Valorização de Resíduos Tyranossaurus - na qual ocorre a triagem, tratamento e homogeneização mecânica de resíduos sólidos urbanos (domiciliares e comerciais) e também de resíduos industriais não-perigosos (Classe IIA e IIB), com capacidade de processamento diária de 1.000 a 2.000 toneladas/dia, resultando em materiais reciclados e CDR - Combustível Derivado de Resíduos que pode ser utilizado por diversos ramos da indústria (siderúrgica, petroquímica, de papel e celulose, sucroalcoleira, entre outras). A Estre opera também uma unidade de co-processamento - RESICONTROL - envolvida com reciclagem energética, cujo processo combina dois ou mais resíduos industriais (resíduos perigosos), visando a produção de um "blend” (mistura homogênea), que pode ser usado como combustível alternativo de alto poder calorífico, sendo considerado portanto uma reciclagem energética. Além disso, a Estre investe desde 2006 em projetos de Mecanismo de Desenvolvimento Limpo (MDL), conforme requisitos do protocolo de Kyoto, através de projetos que visam a redução de emissão dos gases de efeito estufa (GEE), neste caso, o metano. A queima controlada e com transformação em créditos e carbono indica que o foco da estratégia da Estre envolve não apenas a atuação como catalisadora de resíduos, mas também o tratamento e reaproveitamento dos mesmos. A Estre Ambiental tem seis projetos de MDL no Brasil e está elaborando mais quatro. Além disso, será inaugurada em 2013 a primeira Usina Termoelétrica (UTE) de biogás de aterro para geração de eletricidade no grupo.

Os principais usuários da prestação de serviços no tratamento de resíduos sólidos é o setor público, além de grandes empresas privadas com investimento ambientais mais significativos. O setor público é responsável por grandes projetos de saneamento, que incluem a prestação de serviços no setor de engenharia e consultoria de técnicas ambientais, sendo, muitas vezes financiados por organismos internacionais como Banco Interamericano de Desenvolvimento (BID) e outras instituições financeiras. Os Estados e Municípios realizam licitações locais e internacionais para projetos de saneamento e tratamento de resíduos, alguns deles executados na base de concessões. Na área privada, os usuários de serviços na área de engenharia e consultoria ambiental são, em geral, empresas de maior porte, nacionais ou multinacionais. Nos últimos anos os investimentos em grandes segmentos industriais, como papel e celulose, mineração e siderurgia, óleo e gás e petroquímica, visando o atendimento à legislação ambiental tem atenuado as limitações de investimentos no setor público.

A maioria das empresas brasileiras não detém know-how para executar serviços de consultoria ambiental mais complexos. No tocante ao objeto desse estudo, no caso das empresas de Consultoria e Engenharia Ambiental, destacam-se empresas especializadas na elaboração de projetos e na construção de aterros sanitários, incluindo o controle e monitoramento de águas de infiltração, o controle de gás em aterros sanitários, a consultoria em gerenciamento e minimização de resíduos, a eliminação de resíduos perigosos e pesquisas sobre a natureza dos resíduos e das áreas de depósito. Algumas destas empresas também são construtoras de equipamentos ou distribuem equipamentos de fabricantes externos, tendendo a fornecer pacotes mais ou menos "completos" (incluindo projeto, construção, equipamento e operação) de soluções ambientais. Muitas vezes estas empresas tendem a atuar como representantes ou formam algum tipo de parceria tecnológica com empresas estrangeiras, responsáveis pelo fornecimento de know how incorporado ao serviço de consultoria ambiental. Em uma tentativa de sistematização, é possível identificar os seguintes "tipos” de empresas com atuação relevante nos mercados de bens e serviços ambientais:

1) Empresas tipicamente de "engenharia ambiental” de pequeno porte, especializadas em atividades de consultoria e no desenvolvimento de projetos relacionados à avaliação e minimização de impactos, controle e tratamento de emissões, efluentes e resíduos sólidos. Muitas dessas empresas 
originaram-se de "spin-offs" de empresas de saneamento ou de departamentos de engenharia de universidades. Algumas delas, apesar do pequeno porte, são subsidiárias de empresas multinacionais instaladas no país para atender exigências da legislação.

2) Empresas de pequeno-médio porte especializadas na fabricação e instalação de conjunto de equipamentos relativamente padronizados, que podem se adaptar às necessidades específicas de diferentes tipos de clientes. Essas empresas devem possuir uma estrutura de engenharia para dimensionamento de seus projetos e dos equipamentos associados, bem como equipes de campo especializadas para garantir o start-up desses equipamentos com segurança e confiabilidade, provendo também serviços de pós-venda e manutenção. Algumas dessas empresas estruturaram-se também a partir da introdução de alguma inovação relevante incorporada aos equipamentos comercializados. A possibilidade de articular a venda de equipamentos à obtenção de financiamentos, através do cadastramento dessas empresas junto ao FINAME, também constitui fator importante de reforço da competitividade.

3) Empresas de pequeno porte de base tecnológica, muitas delas originárias de spin-offs do meio universitário, que surgiram especificamente para explorar oportunidades associadas a novas soluções inovativas no campo do tratamento de resíduos. Algumas dessas empresas foram criadas ou absorvidas por empresas de maior porte, que as vêem como uma espécie de "porta de entrada" no campo de tecnologias ambientais que podem vir a se constituir em oportunidades atrativas de negócios..

4) Empresas de maior porte especializadas na fabricação de equipamentos e em processos de tratamento de resíduos, efluentes e emissões que são vendidos como sistemas integrados, constituindo unidades adaptadas às exigências particulares de grandes clientes. Essas soluções integradas geralmente são providas em regime turn-key, como no caso de estações de tratamento de efluentes (ETEs), podendo envolver processos de terceirização da operação das unidades. Dentre estas empresas, algumas são multinacionais que têm procurado entrar no Brasil a partir da introdução de "plantas de tratamento demonstrativas", usadas como showroom de suas tecnologias, colocadas estrategicamente em locais de interesse em todo o país.

\section{4 - O Reaproveitamento Energético de Resíduos como Inovação}

A dinâmica inovativa no setor de tratamento de resíduos sólidos articula-se diretamente ao desenvolvimento de soluções ambientais inovadoras incorporadas em produtos, serviços, tecnologias e práticas de gestão. Cabe ressaltar que nem sempre essas soluções ambientais se traduzem em maior lucratividade, pois as atividades de tratamento de resíduos visam, sobretudo, atender a direitos constitucionais assegurados quanto à saúde e ao meio ambiente, sendo usualmente objeto de concessão pública em regime de regulação. Além disso, as empresas atuantes no setor podem optar por incorporar externalidades ambientais e sociais em função de ganhos em boa medida intangíveis, relacionados à melhoria da sua imagem institucional. A implementação de uma solução inovadora em termos do tratamento de resíduos pode, também, representar também uma aposta no futuro, envolvendo a exploração de rotas tecnológicas com potencial atrativo. É nesse contexto que seinsere a possibilidade de reaproveitamento energético de resíduos, que vem se convertendo num importante drive de crecimento do setor.

È importante considerar as principais rotas tecnológicas para aproveitamento energético de resíduos sólidos urbanos, que envolvem tecnologias vinculadas a rotas térmica, biológica e química, ilustradas pela Figura 3. No caso da rota térmica, destaca-se a geração de Combustível Derivado de Resíduos (Refused Derived Fuel - $R D F$ ), resíduo resultante de processo de pré-tratamento de separação e pré-aquecimento, que tem o objetivo de aumentar o poder calorífico do RSU para fins energéticos. Já a Incineração em Massa (Mass Burn), também desenvolvida a partir da combustão, é uma tecnologia exotérmica que utiliza a incineração direta do RSU na presença de oxigênio ou ar para gerar os produtos comercializados, que são normalmente calor e eletricidade. Em termos de processos de Conversão Térmica, destaca-se o processo de Pirólise, um processo endotérmico de decomposição de compostos orgânicos em uma atmosfera deficiente de oxigênio, através de fonte indireta de calor variando entre 
$650^{\circ} \mathrm{C}$ e $1200^{\circ} \mathrm{C}$ e a Gaseificação, um processo exotérmico de decomposição de compostos orgânicos em uma atmosfera com quantidade limitada de ar e oxigênio, realizado no interior de um reator e que gera como principal produto o gás de síntese, composto predominantemente por $\mathrm{CO}$ e $\mathrm{H} 2$, utilizado para cogeração de eletricidade e vapor, bem como para produção de combustíveis líquidos via síntese Fischer Tropsch. No caso da Rota Biológica, destacam-se processos de Compostagem, baseados na biodigestão dos compostos orgânicos presentes em RSU na presença de oxigênio (aeróbia), com o objetivo de estabilizar o material orgânico, gerando como produto final fertilizantes para utilização na agricultura. Já a Digestão Anaeróbia envolve a biodigestão dos compostos orgânicos presentes no RSU na ausência de oxigênio, gerando como produtos finais o biogás, composto sobretudo de metano (CH4) e CO2, além de um produto biodigerido, que também pode ser utilizado como fertilizante na agricultura. No caso da Rota Química, destacam-se processos de Hidrólise Ácida e Depolimerização Catalítica, baseados em tecnologias utilizadas na síntese de biocombustíveis, utilizando como matéria-prima a Biomassa ou produtos derivados de petróleo, onde é possível quebrar polímeros como a celulose e plásticos em cadeias menores para a produção de, por exemplo, etanol de segunda geração e biodiesel.

\section{Figura 3 - Rotas tecnológicas para aproveitamento energético de resíduos sólidos urbanos.}

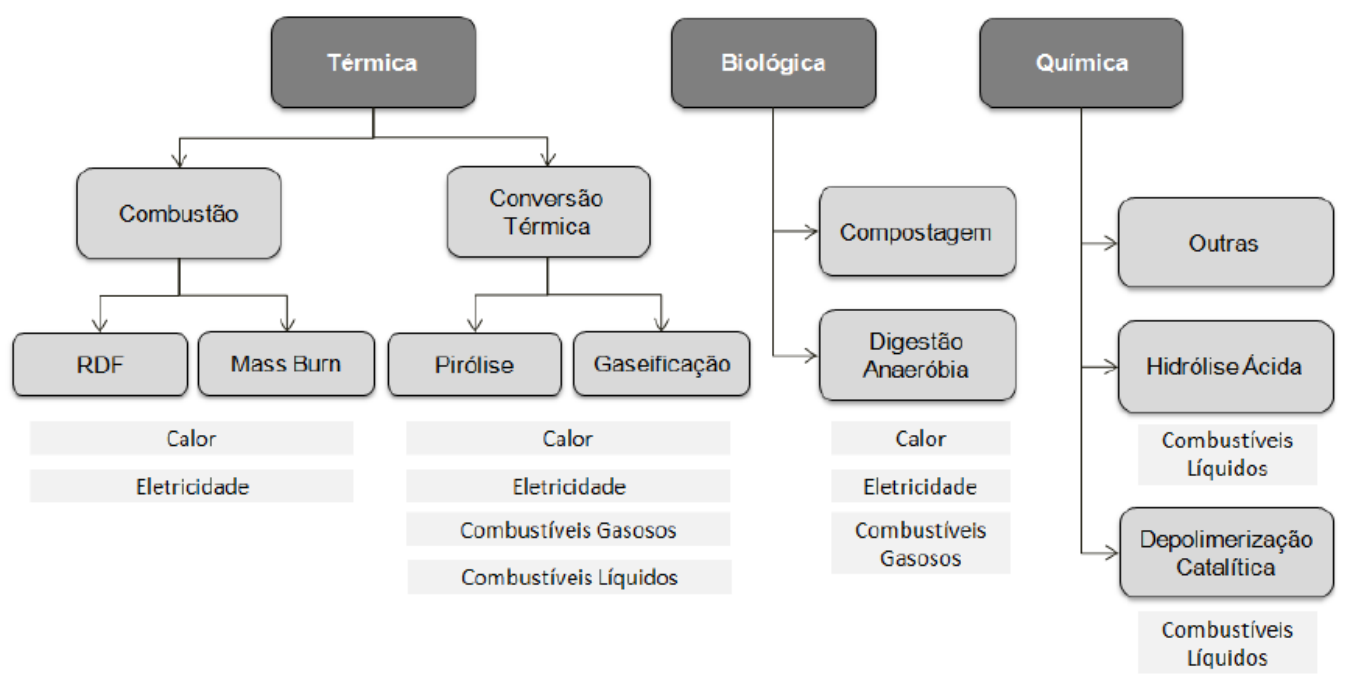

Fonte: Jucá (2012) in: Menezes (2013)

A biodigestão anaeróbia da fração orgânica de RSU é capaz de gerar biogás, eletricidade e biosólido fertilizante. Essa alternativa é particularmente atrativa para a realidade brasileira pelas seguintes razões: 1) RSU com elevada fração de sobras de alimentos (superior a 60\% pp) e teor de umidade, daí com baixo poder calorífico, dificultando a alternativa da incineração, em especial a com recuperação de energia (pois a elevada umidade exige bastante energia para vencer a entalpia de evaporação); 3) características do clima tropical, que reduz os gastos com energia para se manter a faixa de temperatura adequada para a degradação metanogênica; 4) o investimento bem menor exigido pelas plantas de digestão anaeróbia em relação às de incineração; 5) a possibilidade de geração numa única planta de eletricidade, vapor e biossólido com aplicação agrícola; 6) evita-se que muitos recicláveis como plástico e papel/papelão deixem de ser reciclados como ocorre na incineração, o que resulta em perdas de matériasprimas, água virtual e energia embutida nas cadeias de suprimento; 7) a eliminação de riscos ambientais associados a geração de dioxinas e furanos e cinzas contaminadas inerentes à incineração; 8) pelo fato das plantas serem automatizadas e proporcionarem uma melhor segregação do resíduo que ingressa, que em geral é de melhor qualidade que o gerado pela compostagem.

Outra possibilidade contempla a incineração de RSU com recuperação de energia na forma de eletricidade e vapor. Neste caso, destaca-se a possibilidade de queima consorciada com o lodo de estações de tratamento de efluentes (ETEs), que possui maior umidade e menor PCI. Esta alternativa requer, porém, um investimento pesado, com custo operacional elevado e exigência de um volume de RSU de pelo menos 600 t/dia para se tornar exequível. Destaca-se também a possibilidade de implantação de 
outras tecnologias de tratamento térmico como pirólise, gaseificação, fornos de plasma de arco, além da tradicional queima em grelhas do tipo mass burning. Destaca-se também o desenvolvimento de tecnologias específicas para tratamento e reciclagem de resíduos especiais como resíduo eletro-eletrônico e óleo de fritura (que possibilita a fabricação de biodiesel). No tocante à compostagem, além de resíduos domésticos, as unidades podem receber resíduos da indústria de alimento, bebidas e madeireira/moveleira (serragem).

As tecnologias mais avançadas para tratamento de resíduos sólidos e lixiviados envolvem a separação de materiais valiosos, tais como papel, metais, vidro e plásticos, com o intuito de diminuir os custos. Enquanto a incineração adequada de resíduos sólidos urbanos é, em geral, cara, e tende a aumentar os custos, a co-incineração tende a ser uma alternativa mais viável, podendo ser utilizada, por exemplo, para plásticos separados e pneus velhos. Os resíduos biológicos quando recolhidos em separado podem ser direcionados para compostagem ou para a produção de biogás, que pode ser utilizado a geração de eletricidade e calor.

O Brasil ainda não dispõe de infraestrutura para incineração com recuperação de energia para tratamento de resíduos sólidos urbanos. No entanto, nos últimos anos essa opção tem sido objeto de projetos de desenvolvimento tecnológico, de prospecção e de estudos de viabilidade técnica e econômica. Estudo encomendado pelo PNUD e pelo MMA à Arcadis Tetraplan estimou, para 56 localidades brasileiras, a produção de energia potencial, considerando a vazão de biogás no decênio 2010-2020. O resultado demonstrou que há a possibilidade de se ter uma capacidade instalada de geração de $311 \mathrm{MW}$, o que, segundo o estudo, poderia abastecer uma população de 5,6 milhões de habitantes. Esse aumento corresponde a multiplicar por três a capacidade dos projetos de MDL envolvendo geração de energia em aterros no Brasil mapeados pelo IPEA em 2011, que apresentavam uma capacidade instalada de aproximadamente 108 MW (ver Tabela 5). Apesar da viabilidade técnica e econômica de sistemas de geração de energia proveniente do gás de aterro depender de uma quantidade mínima de resíduos aterrados, o incentivo à criação de gestões compartilhadas dos resíduos de vários municípios, conforme propõe a PNRS, deverá causar um ganho de escala capaz de viabilizar não só o aproveitamento de resíduos recicláveis de pequenos municípios, mas também a emissão do gás de aterro como fonte de energia.

Tabela 5- Projetos de MDL envolvendo geração de energia em aterros no Brasil

\begin{tabular}{|c|c|c|c|c|c|}
\hline Nome do projeto & Estado & $\begin{array}{l}\text { Capacidade } \\
\text { instalada de } \\
\text { geração em } \\
\text { MW }\end{array}$ & $\begin{array}{l}\text { Custo de } \\
\text { investimento } \\
\text { US } \$ \mathbf{k W}\end{array}$ & $\begin{array}{l}\text { RCEs } \\
\text { geradas } \\
\text { x1 } \\
\text { mil/ano } \\
\end{array}$ & RCEs sendo vendidas para \\
\hline Gramacho Landfill Gas Project & RJ & Venda do gás & & 852 & \\
\hline Brazil NovaGerar Landfill Gas to Energy Project & RJ & 12 & & 341 & Países Baixos \\
\hline Landfill Gas to Energy Project at Lara Landfill,Mauá, Brazil & SP & 10 & 1.400 & 751 & Países Baixos, Suíça \\
\hline Brazil Marca Landfill Gas to Energy Project & ES & 11 & & 231 & Reino Unido, Japão \\
\hline Bandeirantes Landfill Gas to Energy Project(BLFGE) & SP & 22 & & 1.071 & Alemanha, Países Baixos, Suíça \\
\hline São João Landfill Gas to Energy Project (SJ) & SP & 20 & & 817 & Alemanha e Suíça \\
\hline Estre Itapevi Landfill Gas Project (EILGP) & SP & 3 & & 91 & Reino Unido, Suíça \\
\hline Feira de Santana Landfill Gas Project & BA & & 900 & 43 & \\
\hline Manaus Landfill Gas Project & $\mathrm{AM}$ & 18 & & 1.049 & Reino Unido e Canadá \\
\hline Projeto de Gás de Aterro Tecipar - PROGAT & SP & 6,5 & & 87 & \\
\hline Corpus/Araúna - Landfill Biogas Project. & SP & & 6.021 & 45 & \\
\hline CTR Candeias Landfill Gas Project & $\mathrm{PE}$ & 5,25 & 4.068 & 218 & Espanha \\
\hline Uberlândia Landfills I and II & MG & 2,8 & 4.625 & 111 & \\
\hline Total de capacidade instalada para geração de energia em MW & & 108,55 & & & \\
\hline
\end{tabular}

Fonte: IPEA (2012e)

As emissões geradas pelo setor de resíduos sólidos, quando reaproveitadas, podem gerar ganhos ambientais adicionais em função da estrutturação do "mercado de carbono". No Brasil, a variação percentual das emissões no período de 2005 a 2010, comparada com o período 1995 a 2005, foi de mais de $16 \%$, com os resíduos representando atualmente cerca de $4 \%$ das emissões nacionais de GEE, contra $2 \%$ anteriormente. Neste sentido, observa-se que as práticas de recuperação e queima do biogás reduzem emissões de GEE para a atmosfera, sendo adotadas pelo Protocolo de Quioto como elegíveis ao MDL, com o Brasil possuindo um relevante potencial de desenvolvimento de projetos neste setor. Os projetos de geração de energia em aterro sanitário podem ter um papel importante na consecução dos objetivos do MDL, desde que sejam vencidos desafios referentes ao desenvolvimento competências técnicas 
específicas e estabelecidas normas de regulamentação, em conjunto com a consolidação de um quadro institucional com medidas e/ou instrumentos de política. Os Projetos de MDL em aterros sanitários no Brasil, registrados no CDM registry, são mostrados na Tabela 6. Dos 300 projetos brasileiros de MDL registrados no CDM registry (plataforma de registro de projetos de MDL no website da UNFCCC) em diversos setores, 43 são projetos em aterros sanitários. Os projetos de MDL possuem duplo objetivo: reduzir emissões de GEE e gerar co-benefícios sociais em ambientais no país hospedeiro do projeto.

Tabela 6 - Projetos de MDL em aterros sanitários no Brasil - Maio 2013

\begin{tabular}{|c|c|}
\hline Título do Projeto & Localização \\
\hline Nova Gerar landfill gas & Rio de Janeiro \\
\hline Salvador, Bahia - landfill gas & Bahia \\
\hline Onyx landfill gas - Trémembé, Brazil & São Paulo \\
\hline MARCA landfill gas & Espírito Santo \\
\hline Bandeirantes landfill gas & São Paulo \\
\hline ESTRE Paulínia landfill gas & São Paulo \\
\hline Caieiras landfill gas & São Paulo \\
\hline Lara landfill & São Paulo \\
\hline São João landfill gas & São Paulo \\
\hline Anaconda Project & São Paulo \\
\hline Central de Resíduos do Recreio - landfill gás Project & Rio Grande do Sul \\
\hline Canabrava landfill gas & Bahia \\
\hline Aurá landfill gas & Pará \\
\hline ESTRE Itapevi landfill gás & São Paulo \\
\hline Quitaúna landfill gas & São Paulo \\
\hline Estre Pedreira landfill gas & São Paulo \\
\hline URBAM/ARAUNA landfill gás & São Paulo \\
\hline Embralixo/Araúna - Bragança landfill gas & São Paulo \\
\hline Probiogas - João Pessoa landfill gas & Paraíba \\
\hline Terrestre Ambiental landfill gas & São Paulo \\
\hline CTRVV landfill gas & Espírito Santo \\
\hline Alto-Tietê landfill gas & São Paulo \\
\hline Feira de Santana landfill gas & Bahia \\
\hline Proactiva Tijuquinhas landfill gas & Santa Catarina \\
\hline Central-CTRS/BR.040 landfill gas & Minas Gerais \\
\hline SANTECH - Saneamento \& Tecnologia Ambiental Ltda. - SANTEC landfill gas & Santa Catarina \\
\hline Organoeste Dourados \& Andradina & Mato Grosso do Sul e São Paulo \\
\hline Manaus landfill gas & Amazonas \\
\hline Itaoca landfill gas & Rio de Janeiro \\
\hline CTR Candeias landfill gas & Pernambuco \\
\hline Central de Tratamento de Resíduos Leste (CTL) landfill gas & São Paulo \\
\hline Uberlândia landfills I and II & Minas Gerais \\
\hline CGR Guatapara Landfill Project & São Paulo \\
\hline Natal Landfill Gas to Energy Project & Rio Grande do Norte \\
\hline Projeto de Gás de Aterro TECIPAR - PROGAT & São Paulo \\
\hline ENGEP \& BEGREEN CDM Project at UTGR - Jambeiro Landfill & São Paulo \\
\hline Barueri Energy CDM Project Activity & São Paulo \\
\hline Constroeste Landfill Gas to Energy Project & São Paulo \\
\hline Proactiva CGA Iperó Landfill Gas to Energy Project & São Paulo \\
\hline
\end{tabular}

O tratamento de resíduos sólidos deve incluir opções de revalorização dos resíduos de forma a trazê-los de volta ao ciclo produtivo na forma de materiais (reciclagem mecânica e química), de composto orgânico (compostagem) e/o de energia (biometanização e incineração com recuperação de energia), direcionando-se para a disposição final em aterros apenas os rejeitos que não podem ser tratados e de preferência, inertes. Assim, num sistema maduro de gestão integrada de resíduos sólidos urbanos, a necessidade de aterros é a mínima possível. Por outro lado, as diferentes tecnologias para aproveitamento energético de RSU envolvem vantagens e desvantagens relacionadas ao custo e à eficiência de cada uma das alternativas,que variam também em função de fatores específicos a cada contexto, como o custo da disposição em aterro sanitário e as penalidades que incorrem sobre agentes envolvidos com uma deposição inadequada daqueles resíduos. Já do ponto de vista do arranjo organizacional adequado à viabilização dessas alternativas, cabe destacar, para o aproveitamento das possibilidades descritas, a importância da disseminação de Centrais de Tratamento de Resíduos que integram as diversas possibilidades de reaproveitamento dos mesmos, conforme ilustrado pela Figura 4. 


\section{Figura 4 - Etapas em Central Integrada de Tratamento de Resíduos}

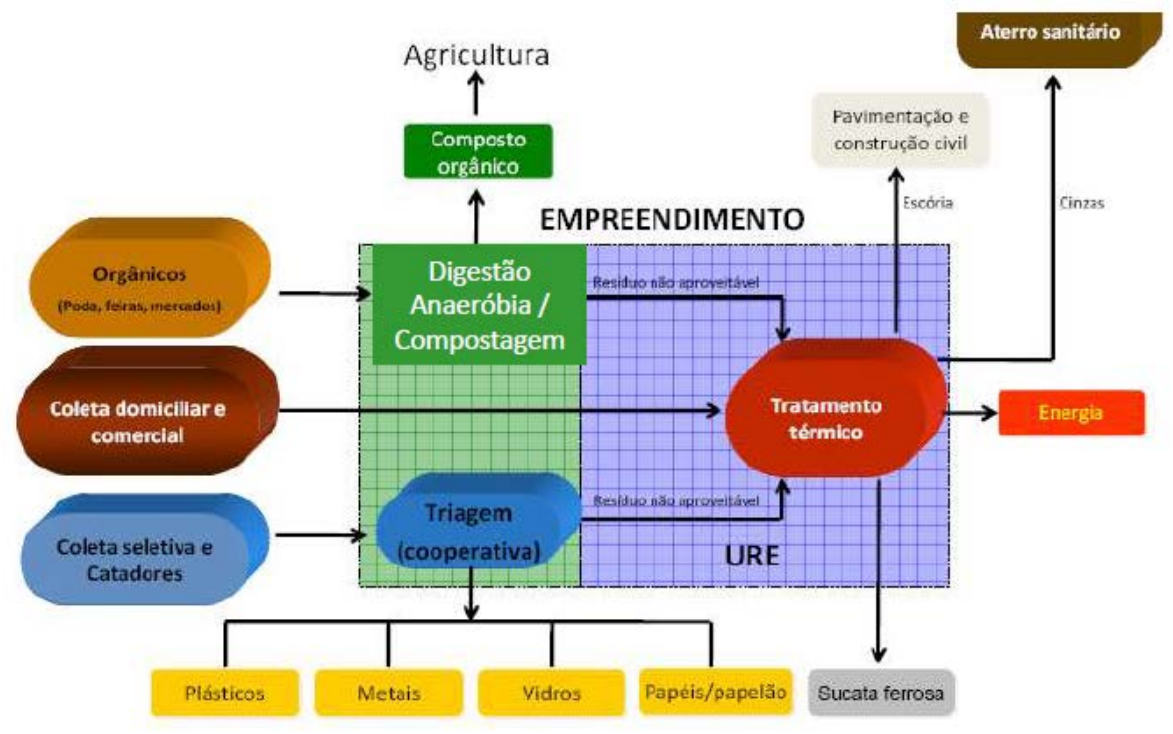

Fonte: Cortez (2012)

\section{Á guisa de conclusão: a relevância de uma política tecnológica setorial}

É importante buscar-se uma maior integração dos esforços inovativos entre as empresas inseridas nos diferentes estágios da cadeia produtiva de tratamento de resíduos - concessionárias de serviços, empresas especializadas no manejo de resíduos, fabricantes de equipamentos, prestadores de serviços especializados, empresas de base tecnológica especializadas em tecnologias específicas, etc. - visando a maior coordenação de seus esforços inovativos. Neste contexto, a formatação de programas e/ou projetos estruturantes e a seleção de tecnologias e áreas prioritárias a partir da definição de uma "agenda tecnológica”, adaptada ao estágio de capacitação e às necessidades de ampliação da cobertura e da qualidade daqueles serviços, parecem ser medidas particularmente importantes. O reaproveitamento energético de resíduos vem se convertendo numa alternativa atrativa tanto do ponto de vista econômicos como amabiental, que desperta crescente intersse do setor empresarial, e que pode ser dinamizado a partir de um manejo adequado dos instrumentos de política. Na mesma direção, destaca-se a intensificação de programas de cooperação entre empresas atuantes no setor e a comunidade acadêmica, particularmente em diversas áreas de engenharia, química, biologia e meio ambiente. O estabelecimento de parcerias entre empresas atuantes no setor e instituições de pesquisa deve contemplar não apenas projetos de pesquisa aplicada em materiais, produtos e processos, assim como para pesquisas básicas em novos paradigmas técnico-científicos, associados a diversos campos das ciências ambientais, que requerem uma capacitação avançada de pesquisadores. Neste sentido, é possível destacar o impacto positivo, em termos da geração de um “efeito-transformação” para o conjunto do setor de programas de pesquisa amplos de natureza colaborativa entre empresas com maior nível de capacitação e instituições de base acadêmica com nível de excelência. O eventual surgimento de "spin-offs" em termos de empresas de base tecnológica a partir desses programas, especializadas em áreas que contemplem soluções tecnológicas adaptas às necessidades do setor empresarial em termos do reaproveitamento energético de resíduos, também deve ser incentivada, inclusive no âmbito do Programa Inova Sustentabilidade.

\section{Bibliografia}

ABETRE - Associação Brasileira de Empresas de Tratamento de Resíduos, "Perfil do setor de tratamento de resíduos”, 2013

ABETRE - Associação Brasileira de Empresas de Tratamento de Resíduos, “Agenda Regulatória dos Resíduos”, 2013b 
ABETRE - Associação Brasileira de Empresas de Tratamento de Resíduos, “Aspectos Econômicos e Financeiros da Implantação de Aterros Sanitários”, 2009

Abramovay, R. Speranza, J.S. Petitgand, C. "Lixo Zero: Gestão de resíduos sólidos para uma sociedade mais próspera”, Instituto Ethos, 2013

ABRELPE - Associação Brasileira de Empresas de Limpeza Pública e Resíduos Especiais, "Panorama dos resíduos sólidos no Brasil”, 2012

ABRELPE - Associação Brasileira de Empresas de Limpeza Pública e Resíduos Especiais, "Panorama dos resíduos sólidos no Brasil”, 2011

Assalie, J.L.S. “Valorização Energética de Resíduos Sólidos no Brasil e Estruturas de Financiamento”, Departamento de Saneamento Ambiental do BNDES, Energy Waste 2012, São Paulo, Nov.2012

Bain \& Company "Estudo Econômico-Financeiro para destinação final de Resíduos Sólidos Urbanos (RSU)”, Fundação Israel Pinheiro, Governo de Minas Gerais, Belo Horizonte - Março de 2012

Bel, D.; Salgosa, A. “A importância da infraestrutura de destinação de resíduos sólidos”, Revista Saneas ,Ano XII - No 43 - Outubro/Novembro/Dezembro/Janeiro de 2012

Bel, D.D. “Conferência de Resíduos Sólidos e Saneamento Ambiental”, ABETRE - Associação Brasileira de Empresas de Tratamento de Resíduos, maio de 2013

Bel, D.D. “Seminário: O aproveitamento do lixo urbano na produção de energia”, ABETRE - Associação Brasileira de Empresas de Tratamento de Resíduos, ACSP -Associação Comercial de São Paulo, junho de 2013

Britto, J.N.P. "Relatório de Acompanhamento Setorial: Competitividade do Setor de Bens e Serviços Ambientais”, ABDI (Agência Brasileira de Desenvolvimento Industrial), MDIC - Ministério do Desenvolvimento, Indústria e Comércio Exterior, Brasília, 2012

Brollo, M.J.; Silva, M.M. "Política e gestão ambiental em resíduos sólidos. Revisão e análise sobre a atual situação no Brasil”, 21ํㅡㄹ Congresso Brasileiro de Engenharia Sanitária e Ambiental, 2001

Cabral, E. “Considerações sobre resíduos sólidos”, IFCE /PGTGA, Disciplina: Gestão de Resíduos Sólidos, 2010

CEMPRE - Compromisso Empresarial para Reciclagem “CEMPRE Review 2013”, 2013

CEMPRE - Compromisso Empresarial para Reciclagem , "Política Nacional de Resíduos Sólidos - Agora é lei”, Folheto, 2010

Cortez, C.L. “Oficina: Avanços Tecnológicos e Estudos de Casos”, CENBIO/IEE/USP, Energy Waste Brasil 2012, São Paulo, 6 de Novembro de 2012

Dias, S.G.”O desafio da gestão de resíduos sólidos urbanos”, Sociedade e gestão, vol.11 nº 1 jan/jun 2012

Economopoulos, A. P. "Planning Tools and Procedures for Rational Municipal Solid Wastes Management”. In: Karagiannidis, A.K. Waste to Energy: Opportunities and Challenges

Fugii, G.M.; Vasconcelos, M.C.; Silva, C.L. "Comparação da gestão de resíduos sólidos urbanos entre dez capitais brasileiras”, ADM 2013 - Congresso Internacional de Administração, 2013

Garcia, E. “Resíduos sólidos urbanos e a economia verde”, Fundação Brasileira para o Desenvolvimento Sustentável - FBDS, 2012

Gouveia, N. "Resíduos sólidos urbanos: impactos socioambientais e perspectiva de manejo sustentável com inclusão social”, Ciência \& Saúde Coletiva, 17(6):1503-1510, 2012

Instituto Ethos, "Política Nacional de Resíduos Sólidos: Desafios e Oportunidades para as Empresas”, Grupo de Trabalho de Resíduos Sólidos do Fórum Empresarial de Apoio à Cidade de São Paulo, 2012

IPEA - Instituto de Pesquisa Econômica e Aplicada "Relatório de pesquisa - Pesquisa sobre Pagamento por Serviços Ambientais Urbanos para Gestão de Resíduos Sólidos”, Diretoria de Estudos e Políticas Regionais, Urbanas e Ambientais - DIRUR, Brasília - 2010

IPEA - Instituto de Pesquisa Econômica e Aplicada, "Diagnóstico dos Instrumentos Econômicos e Sistemas de Informação para Gestão de Resíduos Sólidos - Relatório de pesquisa”, Brasília - 2012

IPEA - Instituto de Pesquisa Econômica e Aplicada, "Diagnóstico dos Resíduos Sólidos Industriais Relatório de pesquisa”, Brasília - 2012d

IPEA - Instituto de Pesquisa Econômica e Aplicada, “Diagnóstico dos Resíduos Sólidos Urbanos Relatório de pesquisa”, Brasília - 2012e 
Jucá, José Fernando Thomé. Tecnologias Disponíveis para Tratamento dos Resíduos Sólidos Urbanos. In: Rio +20 Conferência das Nações Unidas sobre o Desenvolvimento Sustentável, 64 p, Rio de Janeiro, 2012.

Juras, I.A.G.M. “Legislação Sobre Resíduos Sólidos: Comparação da lei 12.305/2010 com a legislação de países desenvolvidos”, Câmara dos Deputados, Brasília - DF, Abril de 2012

Markoski, A.; Prestes,R.R.; Wesendock, C.C.; Ávila, L; Oswald, R.”Gestão ambiental: um legado a logística reversa” $1^{\circ}$ Fórum Internacional Ecoinovar, Santa Maria/RS - 15 a 17 de Agosto de 2012

Mazzer, C.; Cavalcanti, O.A. “Introdução à gestão ambiental de resíduos”, Infarma, v.16, nº 11-12, 2004

Menezes, W.F. “Avaliação tecnológica de geração energética com resíduos sólidos urbanos (RSU) no Brasil”, Dissertação EESP - FGV, São Paulo, 2013

Ministério do Meio Ambiente "Plano Nacional de Resíduos Sólidos - Versão pós Audiências e Consulta Pública para Conselhos Nacionais”, Brasília, fevereiro de 2012

Monteiro, M.J.; Paixão, E.D.; Monteiro, E.A.F., Almeida, M. Silva, T.S.V “Logística reversa: análise diagnóstica da gestão dos resíduos sólidos urbanos em áreas comerciais”, XXXIII Encontro Nacional de Engenharia de Produção, Salvador, BA, Brasil, 08 a 11 de outubro de 2013

Paulino, S.R.; Stuchi Cruz, S.R.S. "Mecanismo de desenvolvimento limpo e inovação tecnológica no setor de resíduos sólidos urbanos”, ALTEC, 2013

Pricewaterhouse Coopers, “Gestão da Limpeza Urbana: Um investimento para o futuro das cidades”, Abril de 2010

Sistema FIRJAN “Manual de Gerenciamento de Resíduos: Guia de procedimento passo a passo”, Rio de Janeiro: GMA, 2006.

Stuchi Cruz, S.R.S; Paulino, S.R. "Perspectivas para inovação em serviços a partir de Projetos de Mecanismo de Desenvolvimento Limpo em Aterros Sanitários com base na Análise do Acesso dos Stakeholders”, ALTEC, 2013

United Nations Environment Programme, “Towards a green economy: Waste - Investing in energy and resource efficiency”, 2011 